\title{
O Curso de Pedagogia e Condições para o Desenvolvimento da Criatividade
}

\author{
Curso de Pedagogia e Criatividade
}

\author{
Maria Emília M. Gonzaga de Souza \\ Eunice M. L. Soriano de Alencar
}

\begin{abstract}
Resumo
O estudo investigou a extensão em que o curso de Pedagogia, segundo seus professores e alunos, tem favorecido o desenvolvimento e expressão da criatividade em seus alunos, bem como barreiras percebidas pelos docentes à promoção de condições favoráveis à criatividade em sala de aula. Participaram da pesquisa 25 professores e 194 estudantes dos quatro últimos semestres. Estes responderam ao Questionário de Avaliação de Procedimentos Docentes e uma questão aberta a respeito do currículo do referido curso, tendo ainda os docentes completado um checklist de barreiras à promoção da criatividade em sala de aula. Observou-se diferença significativa entre a percepção de professores e alunos no que diz respeito à promoção de procedimentos pedagógicos que promovem a criatividade, a favor dos primeiros. As barreiras mais indicadas pelos professores ao desenvolvimento e expressão da criatividade foram relacionadas aos alunos como elevado número de alunos em sala de aula e alunos com dificuldades de aprendizagem.
\end{abstract}

Palavras-chave: Criatividade; Professor; Currículo.

\section{The pedagogy course and conditions for the development of creativity}

\begin{abstract}
The study investigated the extent to which the Pedagogy course has favored the development and expression of students' creativity according to teachers and students, as well as obstacles perceived by teachers to creativity in the classroom. The study subjects were 25 teachers and 194 students of the last four semesters. They filled out the Teaching Procedures Evaluation Questionnaire and an open question referring to the curriculum of the Pedagogy course. Teachers also completed a checklist of obstacles to the promotion of creativity in the classroom. A significant difference between teachers' and students' perception relating to the promotion of pedagogical practices that favor creativity was observed. The most frequently reported obstacles were related to the students, such as great number of students in the classroom and students with learning difficulties.
\end{abstract}

Keyword: Creativity; Teacher; Curriculum.

\section{El curso de pedagogía y condiciones para el desarrollo de la creatividad}

\section{Resumen}

El estudio ha investigado cuanto en el curso de pedagogía, según sus profesores y alumnos, ha favorecido el desarrollo de la expresión de la creatividad en sus alumnos, así como dificultades para promover condiciones favorables para la creatividad en sala de aula consideradas por los docentes. Han participado 25 profesores y 194 estudiantes de los últimos cuatro semestres. Ellos han respondido al cuestionario de evaluación de procedimientos docentes y una pregunta abierta sobre el curriculum del referido curso, habiendo completado también un checklist sobre dificultades para la promoción de la creatividad en clase. Se ha observado diferencia significativa entre la percepción de los profesores y de los alumnos en relación a la promoción de procedimientos pedagógicos que promueven la creatividad, a favor de los primeros. Las dificultades más indicadas por los profesores al desarrollo y expresión de la creatividad han estado relacionadas a los alumnos, como ser el grande número de alumnos por clase y alumnos con dificultades de aprendizaje.

Palabras clave: Creatividad; Profesor, Curriculum. 


\section{Introdução}

Há um reconhecimento crescente do papel da educação para o desenvolvimento da criatividade do indivíduo. Especialmente o professor, como elemento facilitador do desenvolvimento das habilidades criativas do aluno, tem sido apontado por autores diversos, como Alencar (1990, 1995a, 1995b, 2000, 200I, 2002), Alencar e Fleith (2003a), Cropley (1997, 2004), Fleith (200I, 2002), Amabile (1983, 1996), Wechsler (1993, 2002), entre muitos outros. Estes consideram que o referido professor se caracteriza pelo uso de práticas pedagógicas que encorajam os alunos a expressarem novas idéias e a aprenderem de forma independente, que estimulam o aluno a ampliar o seu campo de conhecimento de tal forma que tenha uma base sólida para propor novas idéias, instigando no mesmo a autoconfiança e a coragem para tentar o novo e o inusitado, além de valorizar e reconhecer idéias originais.

Ressalta-se que, se considerarmos ser o objetivo primordial da educação favorecer o desenvolvimento pleno do educando, a criatividade deve ser um dos eixos norteadores da relação ensino-aprendizagem. Com o aprofundamento deste eixo, os atores da educação possibilitarão ao aluno a mobilização do pensamento criativo e a fusão entre o que se aprende na escola, no mundo real e no mundo do trabalho (Wechsler, 1993). Esta mobilização e fusão capacitam o aluno a superar desafios, transformando-os em oportunidades de crescimento pessoal e de outras pessoas.

O curso de formação de professores deveria ser um espaço gerador de profissionais excelentes, aptos a desempenhar, com sucesso, seu papel de construtores da cidadania. Além disso, deveria propiciar um ambiente no qual o aluno-professor fosse constantemente estimulado e desafiado a ultrapassarem os seus limites com segurança, buscando o seu desenvolvimento pleno. Como afirmam Alencar (200I, 2002), Alencar e Fleith (2003a), Martinez (1997, 2002) e Wechsler (1993), a escola deve preparar os alunos para serem pensadores criativos e independentes, aptos a lidar com os desafios que caracterizam o atual momento da História, marcado pela incerteza, instabilidade, mudança e complexidade.
Pensar em um ambiente estimulador da criatividade pressupõe promover espaço para a utopia, aquela que nos faz querer, esperar e trabalhar em busca da realização, mesmo sabendo das possíveis dificuldades e tropeços. O ambiente mais propício à criatividade é aquele permeado de oportunidades e incentivo à expressão de novas idéias, pesquisa, reflexão e fortalecimento de atributos personológicos que se associam à criatividade. Sabe-se que o ser humano é essencialmente busca, tem uma necessidade vital de ser feliz, de atingir a plenitude; e também de intervir no mundo, conhecendo-o e construindo sua história. Portanto, a criatividade está relacionada à realização humana.

Apesar da importância da criatividade ser crescentemente apontada por profissionais da educação, este é um tema pouco explorado nos cursos de Pedagogia. De modo geral, os seus professores o focalizam de modo superficial. A falta de capacitação e incentivo ao professor, no período de sua formação quanto à criatividade, limita sua atuação aos ditames de uma escola conteúdista, mecânica e não desafiadora para o aluno. Isto é sinalizado por Zilber (2002, p. 47) quando afirma que "a escola não incentiva a reflexão, o espírito exploratório. Ao contrário, ela ensina que para cada desafio só há uma resposta: a certa".

Ademais, embora o papel da educação no desenvolvimento da criatividade seja um tema bastante discutido, com ampla literatura sobre o mesmo (Alencar, 1993, 1995a, 1995b, 2001, 2002; Alencar \& Fleith, 2003a; Alencar \& Virgolim, 1994; Briceño, 1998; Cole, Sugioka \& Yamaga-Lynch, 1999; Fleith, 2002; Houtz, 2003; Lilly \& Bramwell-Rejskind, 2004; Martinez, 1997, 2002; Piirto, 1999; Strom \& Strom, 2002; Wechsler, 1993, 2002), observa-se uma escassez de estudos empíricos focalizando a extensão em que professores universitários de cursos diversos vêm promovendo condições favoráveis ao desenvolvimento da capacidade de criar de seus alunos. O nosso interesse pelo tema, aliado à sua relevância, nos levaram ao desenvolvimento do presente estudo. O mesmo teve como objetivos investigar a percepção de professores e alunos do curso de Pedagogia no que diz respeito ao incentivo a distintos aspectos da criatividade nesse curso; diferença entre a percepção 
de professores e estudantes quanto à extensão em que os docentes vêem implementando procedimentos didáticos que incentivam o desenvolvimento e expressão da criatividade dos alunos; barreiras percebidas pelos docentes desse curso à promoção de condições adequadas ao desenvolvimento e expressão da criatividade discente.

\section{Método}

\section{Participantes}

Participaram do estudo 25 professores e 194 alunos dos quatro últimos semestres do curso de Pedagogia de três faculdades particulares do Distrito Federal. Duas dessas faculdades tinham um número muito limitado de alunos no referido curso, o que levou as autoras a coletar dados em três distintas instituições do ensino superior. A escolha dos professores do curso de Pedagogia é justificada por serem responsáveis pela formação didático-pedagógica de futuros docentes do Ensino Fundamental e por influenciarem positiva ou negativamente, direta ou indiretamente, a atuação desses futuros professores.

Optou-se pela escolha dos alunos dos quatro últimos semestres do curso de Pedagogia, pressupondo-se que esses estariam mais aptos a dar informações relativas ao objeto da presente pesquisa, devido ao maior tempo no curso.

Entre os 25 professores que participaram do estudo, 17 (68\%) eram do sexo feminino e 8 (32\%) do sexo masculino. Tinham, em média, 39,9 anos. Dez professores (40\%) tinham entre I e 3 anos de experiência no magistério; 8 (32\%), 4 e 6 anos de experiência docente e 5 (20\%) lecionavam há mais de 12 anos no ensino superior. Dois professores não informaram o tempo de experiência de magistério. Quanto à titulação, 17 (70\%) eram mestres, I doutor e 7 (28\%) tinham o título de especialistas. A carga horária média desses docentes era de 20,24 horas semanais, sendo que a carga horária de II (44\%) docentes era superior a 24 horas semanais.

Entre os 194 estudantes do curso de Pedagogia que participaram do estudo, 164 (84,5\%) eram do sexo feminino e 28 (14,3\%) do sexo masculino (dois participantes não informaram o gênero). A idade média dos alunos era de 29,8 anos, sendo que 57,2\% informaram ter entre 20 e 30 anos. No momento da coleta de dados, $59(30,4 \%)$ cursavam o $5^{\circ}$. semestre, $56(28,8 \%) \circ 6^{\circ}$. semestre, 23 (II,9\%) ○ $7^{\circ}$. semestre e $50(25,8 \%)$ o último semestre de Pedagogia, tendo seis participantes omitido o semestre que cursavam. Cento e sessenta e nove $(87,1 \%)$, além de estudar, trabalhavam, sendo que $31,4 \%$ como docentes e $31,4 \%$ na área administrativa.

\section{Instrumentos}

Utilizou-se o Inventário de Avaliação de Práticas Docentes, construído por Alencar (1995c, 1997) para avaliar a percepção de professores e alunos do curso de Pedagogia no que diz respeito à extensão em que consideravam que diferentes aspectos relacionados com a criatividade vinham sendo implementados nas disciplinas desse curso. Este questionário apresentase em duas versões - uma para o professor e outra para os discentes.

Para a elaboração desse instrumento, Alencar baseou-se em estudos (Alencar, 1990, 1994; Amabile, 1983, 1986; Chambers, 1973; Renzulli, 1992; Torrance, 1965, 1972, 1979, 1987) a respeito de fatores facilitadores e inibidores ao desenvolvimento e expressão da criatividade em sala de aula. O mesmo consta de 19 itens, que são respondidos em uma escala de cinco pontos, variando de discordo totalmente (I) a concordo totalmente (5).

Como descrito anteriormente 0 referido instrumento (Alencar, 1995) era composto originalmente por 23 itens relativos a diversos aspectos, como traços de personalidade que se associam à criatividade, pensamento criativo, metodologia de ensino e condições de aprendizagem que promovem a sua expressão. Esses itens foram avaliados semanticamente, o que resultou na eliminação de um deles e na reformulação de dois outros, apontados como pouco claros. $\mathrm{O}$ instrumento, com 22 itens, foi aplicado a uma amostra de 210 estudantes do ensino superior, com vistas a obter dados para a validação estatística do mesmo. A seguir, foi feito o estudo de sua validação, procedendo-se a uma análise 
fatorial dos componentes principais e rotação varimax para se identificar os fatores que compunham a escala. Por meio desta análise, identificam-se cinco fatores. Entretanto, em apenas um deles (fator I), observouse um número de itens com cargas fatoriais mais significativas (igual ou maior do que 0,30 ). No caso dos demais fatores, a grande maioria dos itens apresentou carga fatorial abaixo deste valor. Tais dados indicaram, portanto, que o instrumento se compunha de um fator mais expressivo. Foi realizada, então, uma segunda análise fatorial com os dois fatores mais expressivos, que apresentaram, na primeira análise, valor eigenvalue igual ou superior a I,5. Nesta segunda análise, observou-se que o valor eigenvalue do fator I foi de 6,72 , explicando este fator $30,6 \%$ da variância total. $O$ fator 2 teve um eigenvalue inferior a um, e por esta razão não foi levado em consideração. Construiu-se, então, o instrumento definitivo com os itens que apresentaram no fator I correlação itemtotal igual ou superior a 0,30 , tendo sido excluídos nesta etapa três itens cuja carga fatorial era abaixo deste valor. Procedeu-se também a uma análise de consistência interna, obtendo-se para o fator I um coeficiente Alfa no valor de 0,90.

Além desse instrumento, os participantes responderam à seguinte questão aberta: Em sua opinião, o currículo teórico e prático do curso de graduação em Pedagogia desta Faculdade tem contemplado o desenvolvimento e a expressão do potencial criativo do estudante? Os professores responderam ainda a um checklist, construído por Alencar e Fleith (2006), com 16 itens referentes a possíveis barreiras, percebidas pelos docentes, em sua prática pedagógica, para a promoção de condições favoráveis ao desenvolvimento e expressão da criatividade do aluno. No checklist, há um espaço para o professor acrescentar, caso julgue pertinente, outras barreiras, além daquelas relacionadas no mesmo.

\section{Resultados}

A Tabela I apresenta a média e desvio-padrão nos itens do Inventário de Avaliação de Práticas Docentes (Professores e Alunos), bem como o valor $t$ de
Student. Como pode ser observado nessa tabela, os professores se auto-avaliaram como implementando distintos procedimentos docentes que promovem a criatividade discente. Nota-se que, em todos os itens, as médias foram igual ou superior a 4,44, com exceção daqueles itens invertidos para o cômputo da média geral, a saber: "Preocupar-se apenas com - conteúdo informativo da disciplina que leciona" $(M=1,68 ; D P=0,99)$ e "Utilizar formas de avaliação que exigem dos alunos apenas a reprodução do conteúdo dado em classe ou contido nos livros textos" $(M=1,36 ; D P=0,49)$. A média geral dos docentes no Inventário foi $4,25(D P=\mathrm{I}, \mathrm{I} \mathrm{I})$.

Nota-se ainda, pela análise da Tabela I, que as médias dos alunos variaram de 3,15 a 3,78, sendo que nos itens invertidos - "Preocupam-se apenas com o conteúdo informativo de sua disciplina" e "Utilizam formas de avaliação que exigem dos alunos apenas a reprodução do conteúdo dado em classe ou contido nos livros textos" - foram 2,76 e 2,7I respectivamente. A média geral no instrumento foi $3,4 \mathrm{I}(D P=\mathrm{I}, 0 \mathrm{I})$, portanto, inferior a 4, que corresponde à opção "concordo".

Para comparar as diferenças entre médias de professores e alunos nos distintos itens do instrumento e na média geral desses dois grupos foi utilizado o teste $t$ de Student (ver Tabela I). Este indicou que os professores apresentaram médias significativamente superiores em todos os itens, com exceção dos itens "Preocupam-se apenas com o conteúdo informativo de sua disciplina" e "Utilizam formas de avaliação que exigem dos alunos apenas a reprodução do conteúdo dado em classe ou contido nos livros textos", em que a média dos alunos foi significativamente superior a dos professores. A avaliação dos docentes sobre a utilização de práticas docentes que estimulam a criatividade dos alunos foi, pois, significativamente mais positiva que a avaliação dos alunos em relação a este mesmo aspecto.

Uma análise das respostas à questão aberta referente ao currículo teórico e prático do curso de Pedagogia no que diz respeito a se este tem contemplado o desenvolvimento do potencial criativo do estudante indicou que, para 10 professores (40\%), o currículo teórico e prático das respectivas faculdades contempla o desenvolvimento do potencial criativo do 
Tabela I - Média, Desvio Padrão, Valor $t$ nos Itens do Questionário de Avaliação de Procedimentos Docentes (Professores e Alunos)

\begin{tabular}{|c|c|c|c|c|c|c|}
\hline \multirow[b]{2}{*}{ Itens do questionário } & \multicolumn{2}{|c|}{ Professores } & \multicolumn{2}{|c|}{ Alunos } & \multirow[b]{2}{*}{$t$} & \multirow[b]{2}{*}{$p$} \\
\hline & $\mathrm{M}$ & $\mathrm{DP}$ & $\mathrm{M}$ & $\mathrm{DP}$ & & \\
\hline $\begin{array}{l}\text { 1- Cultivam nos alunos o gosto pela descoberta e pela } \\
\text { busca de novos conhecimentos. }\end{array}$ & 4,80 & 0,41 & 3,65 & 0,98 & 10,64 & 0,0001 \\
\hline $\begin{array}{l}\text { 2- Fazem perguntas desafiadoras que motivam os alunos } \\
\text { a pensar e a raciocinar. }\end{array}$ & 4,80 & 0,41 & 3,54 & 0,93 & 11,91 & 0,0001 \\
\hline $\begin{array}{l}\text { 3- Estimulam os alunos a analisar diferentes aspectos de } \\
\text { um problema }\end{array}$ & 4,72 & 0,54 & 3,52 & 0,92 & 9,46 & 0,0001 \\
\hline 4- Estimulam a iniciativa dos alunos. & 4,80 & 0,41 & 3,47 & ,95 & 12,45 & 0,0001 \\
\hline $\begin{array}{l}\text { 5- Estimulam os alunos a pensar idéias novas } \\
\text { relacionadas ao conteúdo da disciplina. }\end{array}$ & 4,76 & 0,44 & 3,55 & 0,96 & 10,87 & 0,0001 \\
\hline 6- Promovem a autoconfiança dos seus alunos. & 4,88 & 0,33 & 3,39 & 1,07 & 14,63 & 0,0001 \\
\hline $\begin{array}{l}\text { 7- Estimulam a curiosidade dos alunos através das tarefas } \\
\text { propostas em suas disciplinas. }\end{array}$ & 4,64 & 0,57 & 3,36 & 0,99 & 9,58 & 0,0001 \\
\hline 8- Incentivam a independência de seus alunos. & 4,72 & 0,46 & 3,45 & 0,99 & 10,95 & 0,0001 \\
\hline 9- Desenvolvem nos alunos habilidades de análise crítica. & 4,72 & 0,46 & 3,68 & 0,87 & 9,37 & 0,0001 \\
\hline $\begin{array}{l}\text { 10- Levam os alunos a perceber e conhecer os pontos de } \\
\text { vista divergente sobre o mesmo problema ou te ma de } \\
\text { estudo. }\end{array}$ & 4,56 & 0,71 & 3,57 & 0,94 & 5,10 & 0,0001 \\
\hline 11 - Valorizam as idéias originais de seus alunos. & 4,84 & 0,47 & 3,28 & 1,03 & 13,01 & 0,0001 \\
\hline $\begin{array}{l}\text { 12- Incentivam os alunos a proporem questões relativas } \\
\text { aos temas estudados. }\end{array}$ & 4,52 & 0,65 & 3,48 & 0,97 & 6,99 & 0,0001 \\
\hline $\begin{array}{l}\text { 13- Preocupam-se apenas com o conteúdo informativo de } \\
\text { sua disciplina. }\end{array}$ & 1,68 & 0,99 & 2,76 & 1,19 & 5,02 & 0,0001 \\
\hline $\begin{array}{l}\text { 14- Criam um ambiente de respeito e aceitação pelas } \\
\text { idéias dos alunos. }\end{array}$ & 4,72 & 0,46 & 3,58 & 0,94 & 10,03 & 0,0001 \\
\hline $\begin{array}{l}\text { 15- Dão tempo aos alunos para pensar e desenvolver } \\
\text { idéias novas. }\end{array}$ & 4,64 & 0,49 & 3,49 & 1,02 & 9,40 & 0,0001 \\
\hline $\begin{array}{l}\text { 16- Dão chances aos alunos para discordar de seu ponto } \\
\text { de vista. }\end{array}$ & 4,64 & 0,49 & 3,36 & 1,02 & 10,45 & 0,0001 \\
\hline $\begin{array}{l}\text { 17- Utilizam formas de avaliação que exigem dos alunos } \\
\text { apenas a reprodução do conteúdo dado em classe ou } \\
\text { contido nos livros textos. }\end{array}$ & 1,36 & 0,49 & 2,71 & 1,21 & 10,28 & 0,0001 \\
\hline $\begin{array}{l}\text { 18- Apresentam vários aspectos de uma questão que está } \\
\text { sendo estudada. }\end{array}$ & 4,56 & 0,58 & 3,49 & 0,98 & 7,81 & 0,0001 \\
\hline $\begin{array}{l}\text { 19- Procuram diversificar as metodologias de ensino } \\
\text { utilizadas em suas disciplinas. }\end{array}$ & 4,44 & 0,65 & 3,15 & 1,13 & 8,37 & 0,0001 \\
\hline
\end{tabular}

aluno, enquanto que para outros $10(40 \%)$, contempla parcialmente e para dois (9\%), não contempla. Três professores deixaram de responder à questão.
Como justificativa para a resposta afirmativa, os docentes se reportaram a distintos aspectos da instituição, características do aluno, comportamentos 
do professor e currículo do curso de Pedagogia, como ilustrado nas seguintes respostas:

"Esta faculdade proporciona total liberdade para o professor desenvolver suas aulas, diversificando suas metodologias, unindo teoria e prática. Portanto, tem contemplado a expressão do potencial criativo do aluno".

“(...) O aluno interessado e comprometido tem todas as chances de desenvolver o seu potencial criativo".

"Os professores estão constantemente procurando utilizar recursos de ensino e metodológicos diversificados. As atividades em sala de aula são sempre motivadoras e o clima de trabalho é agradável e incentivador".

Os docentes que concordaram parcialmente, se reportaram a distintos aspectos, como projeto pedagógico, desafio de se implementar na prática $o$ currículo proposto e necessidade de maior incentivo à participação docente e discente em atividades culturais e científicas. Exemplos de respostas são apresentados a seguir:

"Acho que poderia ser melhor contemplado se, para além das atividades formais de sala de aula, fosse garantido para alunos e professores a participação em atividades culturais e científicas mais abrangentes".

“Tem contemplado parcialmente, porém, é preciso implementar atividades que favoreçam o desenvolvimento desse potencial em maior escala. Talvez, seja necessário um projeto pedagógico mais dedicado a esse item, bem como à promoção de eventos para esse fim".

Os docentes, que responderam negativamente, indicaram aspectos da instituição e do currículo para justificar sua resposta, como ilustrado a seguir:

“É um programa muito rígido, com pouco espaço para a iniciativa do professor. Mesmo quando o aluno pode ter iniciativa, isto é cortado pela burocracia”.
"O curso é demasiado teórico. Existem poucas oportunidades para a oferta de atividades diversificadas e de integração das diversas disciplinas".

Por outro lado, uma análise das respostas dos alunos à questão relativa à extensão em que o currículo teórico e prático do curso de Pedagogia tem contemplado o desenvolvimento do potencial criativo do estudante indicou que 66 (34,0\%) responderam afirmativamente, 65 (33,5\%) consideraram que o currículo contempla apenas em parte o potencial de criatividade e 34 (I7,5\%) responderam negativamente. Vinte e nove $(15,0 \%)$ não responderam à questão. Distintos aspectos relativos à instituição, ao professor, ao aluno e ao currículo foram apontados para justificar tanto as respostas afirmativas quanto as respostas negativas, como ilustrado a seguir. A primeira delas de um participante que respondeu afirmativamente, a segunda de um que considerou que o currículo contempla apenas parcialmente o desenvolvimento do potencial criativo do aluno e a terceira de um participante que respondeu negativamente:

"Os professores da Instituição (alguns) têm procurado desenvolver (estimular) em seus alunos a criatividade e o senso crítico, preparando-os para trabalhar com crianças".

“Na teoria, temos muitas oportunidades de saber como desenvolver cada potencial. Só que nos falta maiores confrontos com a prática (realidade) para desenvolver a autonomia de cada potencial criativo existente em cada um de nós'.

“Não. Alguns professores estão em uma linha de raciocínio teórico. Estão trabalhando mais teoria e esquecendo a prática. As aulas estão cansativas, estamos desestimulados. Alguns professores estão ministrando suas aulas em regime militar. Proponho que eles tenham um pouco mais de dinamicidade".

A Tabela 2 apresenta a freqüência e porcentagem nas barreiras apontadas pelos professores à promoção de condições adequadas ao desenvolvimento/ expressão da criatividade de seus alunos em sala de 
Tabela 2 - Barreiras apontadas pelo professor à promoção de condições adequadas ao desenvolvimento/ expressão da criatividade do aluno

\begin{tabular}{|c|c|c|}
\hline Barreiras & $f$ & $\%$ \\
\hline Elevado número de aluno em sala de aula & 14 & 56 \\
\hline $\begin{array}{l}\text { Alunos com dificuldades de aprendizagem em } \\
\text { sala de aula. }\end{array}$ & 14 & 56 \\
\hline Desinteresse do aluno pelo conteúdo ministrado. & 8 & 32 \\
\hline $\begin{array}{l}\text { Extensão do programa a ser cumprido no decorrer } \\
\text { do semestre. }\end{array}$ & 5 & 20 \\
\hline $\begin{array}{l}\text { Presença de alunos indisciplinados que pe rturbam } \\
\text { o trabalho docente. }\end{array}$ & 5 & 20 \\
\hline $\begin{array}{l}\text { Desconhecimento de práticas pedagógicas que } \\
\text { poderiam ser utilizadas para propiciar o } \\
\text { desenvolvimento da criatividade do aluno. }\end{array}$ & 4 & 16 \\
\hline $\begin{array}{l}\text { Escassez de material didático disponível na } \\
\text { faculdade. }\end{array}$ & 4 & 16 \\
\hline $\begin{array}{l}\text { Falta de orientação por parte da coordenação } \\
\text { pedagógica da faculdade no que diz respeito a } \\
\text { como favorecer o desenvolvimento da } \\
\text { criatividade do aluno. }\end{array}$ & 2 & 8 \\
\hline $\begin{array}{l}\text { Insegurança para testar novas práticas } \\
\text { pedagógicas. }\end{array}$ & 1 & 4 \\
\hline
\end{tabular}

aula. Como pode ser observado (Tabela 2), as barreiras mais indicadas pelos professores, foram o elevado número de alunos em sala de aula, alunos com dificuldades de aprendizagem em sala de aula e desinteresse do aluno pelo conteúdo ministrado; as duas primeiras apontadas por $56 \%$ e a terceira por $32 \%$ dos professores.

Apenas um professor apontou a insegurança para testar novas práticas pedagógicas como barreira que vem encontrando em sua prática docente para promover a criatividade em sala de aula. Ademais, um número reduzido de docentes sinalizou o desconhecimento de práticas pedagógicas para promover a criatividade que poderiam ser utilizadas em sala de aula ( $N=4 ; 16 \%)$; aspectos da instituição em que trabalhavam, como falta de material didático $(N=4 ; 16 \%)$; e falta de orientação por parte da coordenação pedagógica da Faculdade, no que diz respeito a como favorecer o desenvolvimento da criatividade do aluno $(\mathrm{N}=2 ; 8 \%)$.

Constatou-se que vários itens do checklist relativos ao professor, como "desconhecimento de textos (livros e/ou artigos) a respeito de como implementar a criatividade em sala de aula", "falta de entusiasmo pela atividade docente" e à instituição, como "falta de apoio institucional na implementação de projetos inovadores" não foram apontados pelos participantes do presente estudo. 


\section{Discussão}

Constatou-se, no estudo, diferenças entre a percepção de professores e alunos do curso de Pedagogia no que diz respeito à extensão em que os primeiros vêm implementando práticas pedagógicas que promovem a criatividade, tendo sido a avaliação dos professores muito mais positiva do que a de seus alunos.

Resultados similares a estes foram anteriormente obtidos por Silva e Alencar (2003), em uma amostra de professores de alunos do curso de Enfermagem de uma universidade pública e por Alencar e Fleith (2004) em um estudo com professores e alunos de distintos cursos do ensino superior. Uma possível explicação para tal discrepância é o traço comum do ser humano de dar respostas socialmente valorizadas, em um esforço de transmitir uma impressão positiva de si mesmo. Ademais, em pesquisas com estudantes de graduação, Alencar (1995c, 1996, 1997), observou que, segundo esses estudantes, seus professores não vinham utilizando práticas pedagógicas que promovem a criatividade, além de considerarem os seus professores como pouco ou muito pouco criativos. Nota-se que, segundo vários autores como Martinez (2002), Strom e Strom (2002) e Wechsler (1998, 200I), predomina uma cultura de aprendizagem que limita a expressão criativa na maioria das instituições educacionais.

Por outro lado, no presente estudo, embora uma discrepância tenha sido observada, a avaliação dos discentes foi acima do ponto médio, o que aponta uma percepção mais positiva do que a observada nos primeiros estudos de Alencar com estudantes universitários e em dissonância com o sinalizado por Briñeno (1998) de que os professores tendem a castigar ou não reforçar positivamente a conduta criativa de seus alunos optando por condutas conformistas. Também Strom e Strom (2002) consideram que as regras que orientam a instrução em todos os níveis de ensino devem ser revistas para uma maior promoção da criatividade, sugerindo várias mudanças como, por exemplo, no sentido de se reduzir a prioridade na retenção da informação, oferecer oportunidades ao aluno para praticar suas habilidades criativas, reconhecer e valorizar a curiosidade e o questionamento dos alunos e promover a aprendizagem centrado no mesmo. De forma similar, Alencar (200I), Fleith (200I, 2002), Lilly e Gramwell-Rejskind (2004) e Wechsler (200I) apontam como características do ensino criativo o encorajamento da individualidade, independência, curiosidade e habilidades criativas do aluno, paralelamente à provisão de um clima seguro que estimula o aluno a correr riscos e expressar idéias inusitadas.

Observou-se também que mais da metade dos docentes e estudantes concordou que o potencial criativo do aluno vinha sendo contemplado, total ou parcialmente, no currículo teórico e prático do curso de Pedagogia das instituições onde lecionavam ou estudavam. Uma análise das respostas desses participantes indicou, entretanto, que muitos deles confundiram currículo com postura do professor, metodologia de ensino e mesmo falta de interesse dos alunos. Outros fizeram críticas relevantes ao currículo da instituição de ensino na qual lecionavam, apontando, por exemplo, falta de objetivo do curso e de projetos interdisciplinares.

Constatou-se ainda, no estudo, que as barreiras mais indicadas pelos docentes do curso de Pedagogia à promoção da criatividade em sala de aula foram aquelas relacionadas ao próprio aluno - "elevado número de alunos em sala de aula", "alunos com dificuldades de aprendizagem" e "desinteresse do aluno pelo conteúdo ministrado". Estes resultados estão em congruência com outros encontrados por Carvalho e Alencar (2004), em uma amostra de professores de Geografia e por Viana e Alencar (2006) com tutores de cursos de educação online. Tais barreiras refletem dificuldade por parte do professor em manter a atenção, interesse e participação do aluno, o que poderia ser um elemento facilitador à aprendizagem em sala de aula.

Ademais, várias barreiras diretamente relacionadas ao professor, incluídas no checklist, como "Poucas oportunidades para discutir e trocar idéias com colegas sobre estratégias de ensino", "Desconhecimento de textos (livros e/ou artigos) a respeito de como implementar a criatividade em sala de aula" e "Falta de entusiasmo pela atividade docente" não foram apontadas pelos docentes participantes do estudo. Estes, pois, 
parecem se considerar preparados para propiciar as condições necessárias ao desenvolvimento e expressão da criatividade do aluno. Resultados similares a estes foram também obtidos por Carvalho e Alencar (2004), em um estudo com professores de Geografia. Tais resultados sugerem uma possível resistência do professor em ser avaliado, denotando dificuldade em admitir como possíveis barreiras à promoção de condições adequadas à criatividade em sala de aula, características pessoais. É mais fácil deslocar para o aluno, a escola ou a sociedade, os fatores que dificultam o trabalho docente no que diz respeito à promoção da criatividade.

\section{Referências}

Alencar, E. M. L. S. (1990). Como desenvolver o potencial criador: um guia para a liberação da criatividade em sala de aula. Petrópolis, RJ: Vozes.

Alencar, E. M. L. S. (1993). Thinking in the future: The need to promote creativity in the educational context. Gifted Education International, 9, 93-96.

Alencar, E. M. L. S. (1994). Creativity in the educational context: two decades of research. Gifted and Talented International, 9, 4-7.

Alencar, E. M. L. S. (1995a). Challenges to the development of the creative talent. Gifted and Talented International, 6, 82-90.

Alencar, E. M. L. S. (1995b). Criatividade. Brasília,DF: Editora da Universidade de Brasília.

Alencar, E. M. L. S. (1995c). Developing creative abilities at the university level. European Journal for High Ability, 6, 82-90.

Alencar, E. M. L. S. (1996). University students' evaluation of their own level of creativity, their teachers' and colleagues' level of creativity. Gifted Education International, I I, I 28- I30.

Alencar, E. M. L. S. (1997). O estímulo à criatividade no contexto universitário. Psicologia Escolar e Educacional, I, 29-37.

Alencar, E. M. L. S. (2000). O perfil do professor facilitador e do professor inibidor da criatividade segundo estudantes de pós-graduação. Boletim da Academia Paulista de Psicologia, 19, 84-94.

Alencar, E. M. L. S. (200I). A escola e o desenvolvimento do talento criativo. Em E. M. L. S. Alencar (Org.), Criatividade e educação de superdotados (pp. 45-58). Petrópolis,RJ: Vozes.

Alencar, E. M. L. S. (2002). O contexto educacional e sua influência na criatividade. Linhas Críticas, 8, I65-I78.

Alencar, E. M. L. S., \& Fleith, D. S. (2003a). Criatividade. Múltiplas perspectivas. Brasilia, DF: Editora da Universidade de Brasília.

Alencar, E. M. L. S., \& Fleith, D. S. (2004). Creativity in university courses: Perceptions of professors and students. Gifted and Talented International, 19, 24-28.

Alencar, E. M. L. S., \& Fleith, D. S. (2006). Práticas pedagógicas que promovem a criatividade segundo professores do ensino fundamental. Relatório de pesquisa apresentado ao Conselho Nacional de Desenvolvimento Científico e Tecnológico (CNPq).

Alencar, E. M. L. S., \& Virgolim, A. M. R. (Orgs.). (1994). Criatividade: expressão e desenvolvimento. Petrópolis,RJ: Vozes.

Amabile, T. M. (1983). The social psychology of creativity. New York,NY: Springer-Verlag.

Amabile, T. M. (1996). Creativity in context. Boulder, CO: Westview Press.

Briceño, E. D. (1998). La creatividad como um valor dentro del proceso educativo. Psicologia Escolar e Educacional, 2, 43-5I.

Carvalho, O., \& Alencar, E. M. L. S. (2004). Elementos favorecedores e inibidores da criatividade na prática docente, segundo professores de Geografia. Psico, 35 , 2|3-22I.

Chambers, J. A. (1973). College teachers: Their effect on creativity of students. Journal of Educational Psychology, 65 , 326-334.

Cole, D. G., Sugioka, H. L., \& Yamagata-Lynch, L. C. (1999). Supportive classroom environments for creativity in higher education. The Journal of Creative Behavior, 33, 277-292.

Cropley, A. J. (1997). Fostering creativity in the classroom: General principles. Em A. M. Runco (Org.), The creativity research handbook (pp. 83-I I4). Creskill, NJ: Hampton Press.

Cropley, A. J. (2004). Creativity in education \& learning. A guide for teachers and educators. London: RoutledgeFalmer.

Fleith, D. S. (200I). Criatividade: novos conceitos e idéias, aplicabilidade à educação. Cadernos de Educação Especial, 17, 55-61. 
Fleith, D. S. (2002). Ambientes educacionais que promovem a criatividade e a excelência. Sobredotação, 3, 27-39.

Houtz, J. (2003). The Educational Psychology of creativity. Creskill. NJ: Hampton Press.

Lilly, F. R., \& Bramwell-Rejskind, G. F. (2004). The dynamics of creative teaching. The Journal of Creative Behavior, 38, $102-$ 124.

Martinez, A. M. (1997). Criatividade, personalidade e educação. Campinas,SP: Papirus.

Martinez, A. M. (2002). A criatividade na escola: três direções de trabalho. Linhas Críticas, 8, 189-206.

Piirto, J. (1999). A survey of psychological studies in creativity. Em A. S. Fishkin, B. Cramond \& P. Olszewski-Kubilius (Orgs.), Investigating creativity in youth. Research and methods (pp. 27-48). Creskill, NJ: Hampton Press.

Renzulli, J. S. (1992). A general theory for the development of creative productivity in young people. Em F. J. Mönks \& W. A. M. Peters (Eds.), Talent for the future (pp. 5I-72). Assen, Netherlands: Van Gorcum.

Silva, O. J. (2003). Criatividade no ensino superior de Enfermagem à luz dos componentes do processo ensinoaprendizagem. Revista Brasileira de Enfermagem, 56, 610614.

Silva, O. \& Alencar, E. M. L. S. (2003). Criatividade no ensino de Enfermagem - enfoque triádico: professor, aluno, currículo. Revista Brasileira de Enfermagem, 56, 6I0-6I4.

Strom, R. D., \& Strom, P. S. (2002). Changing the rules: Education for creative thinking. The Journal of Creative Behavior, 36, I83-200.
Torrance, E. P. (1965). Rewarding creative behavior. Experiments in classroom creativity. Englewood Cliffs, NJ: PrenticeHall.

Torrance, E. P. (1972). Can we teach children to think creatively? Journal of Creative Behavior, 6, I I4-I43.

Torrance, E. P. (1979). The search for satori and creativity. Buffalo, NY: Bearly Limited.

Torrance, E. P. (1 987). Teaching for creativity. Em S. G. Isaken (Org.), Frontiers of creativity research. Beyond the basics (pp. 189-2I5). Buffalo, NY: Bearly Limited.

Vianna, C. G. V., \& Alencar, E. M. L. S. (2006). Creativity and barriers to its expression in online education course. Gifted Education International, 2I, 64-62.

Wechsler, S. M. (1993). Criatividade, descobrindo e encorajando. Campinas,SP: Editorial Psy.

Wechsler, S. M. (1998). Pensando criativamente na universidade. Psicologia Escolar e Educacional, 2, 67-72.

Wechsler, S. M. (200I). A educação criativa: possibilidades para descobertas. Em S.Castanho \& M. E. Castanho (Orgs.), Temas e textos em metodologias do ensino superior (pp. 165-170). Campinas: Papirus.

Wechsler, S. M. (2002). Criatividade e desempenho escolar: uma síntese necessária. Linhas Críticas, 8, I79-I88.

Zilber, S. (2002). Seja criativo. Vencer, 36, 46-60.

Recebido em: 28/03/2006

Revisado em: 24/05/2006

Aprovado em: 10/06/2006

Sobre as autoras

Maria Emília Gonzaga de Souza é mestre em Psicologia pela Universidade Católica de Brasília.

Eunice M. L. Soriano de Alencar (ealencar@pos.ucb.br) é doutora em Psicologia e docente da Universidade Católica de Brasília.

Endereço para correspondência

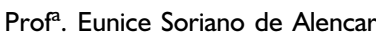

Programa de Mestrado em Educação

Universidade Católica de Brasília

SGAN 916 Módulo B Asa Norte

70790-160 Brasília, DF 